\title{
Efficacy and Safety of Gabapentine and Duloxetine in Diabetic Peripheral Neuropathic Pain
}

\author{
Hussain Ahmad ${ }^{* 1}$, K. M. Hafizur Rahman², Miftaul Jannat Chowdhury ${ }^{3}$, \\ Monharul Islam Bhuiya ${ }^{4}$, Nurjahan Ferdous 5 , Md. Abu Nayeem Chowdhury ${ }^{6}$
}

\begin{abstract}
:
Introduction: Diabetic peripheral neuropathy (DPNP) is not uncommon now a days. As the pathophysiology is not completely understood, symptoms relief is still the main goal of treatment. Gabapentine and Duloxetine are being using around the world for this purpose. But clinical data regarding its efficacy and safety are not sufficiently available. Materials and Methods: This prospective comparative clinical study conducted in Sylhet MAG Osmani Medical College and Sylhet Diabetic Hospital, Bangladesh from January 2013 to December 2013. Diagnosis of DPNP confirmed by Michigan Neuropathy Screening Instrument (MNSI) and Douleur Neuropathic en-4 (DN4). Patients were treated by Gabapentine (Group-A) and Duloxetine (Group-B); and followed up at 4th, 8th and 12th week of treatment using 11-point numerical pain rating scale (NRS), clinical global impression of change (CGIC) score and patient's global impression of change (PGIC) score. Results: A total of 72 patients with DPNP were recruited. Final comparison was done in 64 patients -33 in Group-A and 31 in Group-B. Changes in NRS $(p=<0.001)$, CGIC $(p=$ $<0.001)$ and PGIC $(p=<0.001)$ were statistically significant during the course of treatment. However, inter-group variation of NRS, CGIC and PGIC were not statistically significant at the beginning and 4th, 8th and 12th week of treatment. Insignificant adverse effects were noted between the groups in this study except constipation $(p=0.022)$ and nausea-vomiting $(p=0.01)$ of Duloxetine taking group. Conclusion: Gabapentine and Duloxetine are equally effective in the treatment of DPNP with good safety profile.
\end{abstract}

Key words: Gabapentine, Duloxetine, Efficacy, Safety, Neuropathy.

Number of Tables: 02; Number of Figures: 03; Number of References: 37; Number of Correspondences: 05.

*1. Corresponding Author: Dr. Hussain Ahmad Associate Professor

Department of Pharmacology and Therapeutics Sylhet Women's Medical College, Sylhet.

Mobile: +8801716-725485.

E-mail: dr.hussainjmc@gmail.com

2. Dr. K. M. Hafizur Rahman

Lecturer

Department of Pharmacology and Therapeutics Sylhet Women's Medical College, Sylhet.

3. Dr. Miftaul Jannat Chowdhury

Associate Professor

Department of Pharmacology and Therapeutics Sylhet Women's Medical College, Sylhet.

4. Dr. Monharul Islam Bhuiya

Assistant Professor

Department of Medicine

Sylhet Women's Medical College, Sylhet.

5. Dr. Nurjahan Ferdous

Lecturer

Department of Pharmacology and Therapeutics Sylhet Women's Medical College, Sylhet.

6. Dr. Md. Abu Nayeem Chowdhury

Professor

Department of Pharmacology and Therapeutics

Sylhet Women's Medical College, Sylhet.

\section{Introduction:}

Diabetes Mellitus (DM) is an Endocrine and metabolic disorder characterized by hyperglycemia. The earlier onset and increasing prevalence of diabetes appear as an important public health issue. Recent estimates suggest that of the total cost of diabetes in 2007 is $\$ 174$ billion, one-third ( $\$ 58$ billion) was for the care of diabetes-related chronic complications and was twice the cost of direct diabetes treatment ${ }^{1}$. It was estimated that the developing countries will bear the brunt of diabetes epidemics in the $21 \mathrm{st}$ century ${ }^{2}$.

Patients with long-standing diabetes are in risk of developing a variety of complications. About $25 \%$ of people with Type 2 Diabetes Mellitus (T2DM) have evidence of diabetes complications at the time of initial diagnosis ${ }^{3}$. Micro-vascular complications of diabetes include retinal, renal, and possible neuropathic disease. Macro-vascular complications include coronary artery and peripheral vascular disease. Diabetic neuropathy affects both autonomic and peripheral nerves ${ }^{4}$.

Among various complications, diabetic peripheral neuropathic pain (DPNP) is one of the most common causes of neuropathic pain $^{5}$. It affects about $10 \%$ to $47 \%$ of patients with diabetes in the world and $28.5 \%$ patients with diabetes in the U.S ${ }^{6,7}$. Chronic painful diabetic neuropathy affects $16.2 \%$ in UK, ${ }^{8} 24.0 \%$ in Sri Lanka $^{9}, 14.0 \%$ in Turky $^{10}, 8 \%$ in France ${ }^{11}, 14 \%$ in Belgium ${ }^{12}$, $29 \%$ in India ${ }^{13}$, and $39.6 \%$ in Pakistan ${ }^{14}$ from all the diabetic patients.

The DPNP prevalence in Bangladesh was estimated 19.7\%, male 
was $20.9 \%$ and female was $18.7 \%$ of diabetic patients. The prevalence rate increased with increasing age (from $11.1 \%$ in the 23-40 years-old group to $32.3 \%$ in the $60-80$ years-old group) and duration of diabetes (from 14.1\% in patients with 5 -years to $29.2 \%$ in patients with $9-11$ years' duration $)^{15}$

The factors leading to the development of diabetic neuropathy are not understood completely, and multiple hypotheses have ben postulated. It is generally accepted to be a multifactorial process. Development of symptoms depends on many factors, such as total hyperglycemic exposure and other risk factors such as elevated lipids, blood pressure, smoking, increased height, and high exposure to other potentially neurotoxic agents such as ethanol. Genetic factors may also play a role. Important contributing bio-chemical mechanisms in the development of the more common symmetrical forms of diabetic poly-neuropathy likely include the polyol pathway, advanced glycation end products, and oxidative stress ${ }^{16}$.

DPNP ravages patient's health and life through its tingling (paraesthesias) pain, burning pain, shooting pain, lancinating pain, contact pain, pain on walking, sensations of heat or cold in the feet, persistent achy feeling in the feet, and cramp-like sensations in the lags ${ }^{17,18}$. These symptoms often deprive patients from sleep, conducting normal daily activities, and maintaining full employment, therefore, negatively affect their quality of life ${ }^{19}$.

Several pharmacological agents have been used in treatment of DPNP including Tri-cyclic anti-depressants, selective serotonin re-uptake inhibitors, serotonin-norepinephrine re-uptake inhibitors (SNRI), anti-convulsants, opioids, non-steroidal anti-inflammatory drugs, and others $^{20,21}$. So far, only Duloxetine (SNRI) and Gabapentine (Anti-convulsant) are approved by the Food and Drug Administration in the USA for the management of DPNP. Gabapentine is believed to exert its analgesic effect via reduction of calcium influx through its binding to the a-2presynaptic voltage gated calcium channels, which in turn reduces the release of excitatory neurotransmitters associated with neuropathic pain mechanism ${ }^{22}$; while Duloxetine is a dual re-uptake inhibitor of serotonin and nor-epinephrine neurotransmitters which modulate descending inhibitory pain pathways ${ }^{23}$. The efficacy and safety of Gabapentine and Duloxetine in DPNP management have been studied in many clinical trials, and several studies have also assessed the use of Duloxetine or Gabapentine in real-world practice $^{24,25}$.

Bothe of these drugs have been shown to be effective in clinical trials in DPNP. A recent meta-analysis, in which Duloxetine was compared to Gabapentine in the treatment of DPNP, concluded that the two drugs exhibit comparable efficacy and tolerability. However, to the best of our knowledge, no comparative studies have been carried out between Gabapentine and Duloxetin in Bangladeshi population on DPNP. Therefore, this study was aimed to evaluate the efficacy and safety of Gabapentine and Duloxetine in patients with DPNP in Bangladesh.

\section{Materials and Methods :}

This prospective comparative clinical study was conducted in the Department of Pharmacology and Therapeutics of Sylhet MAG Osmani Medical College and Sylhet Diabetic Hospital,Bangladesh from January 2013 to December 2013. Newly diagnosed patient's neuropathy for more than three months who has history of DM and a pain score of at least 4 on the 10 numeric pain rating scale (NRS) were included in this study. Patient's with other comorbidities (like hepatic, cardiac and renal failure), history of amputation of limb (or part of a limb), pregnancy and lactating mother were excluded.

Data collected at the starting of the study and followed-up at the end of 4th, 8th and 12th week, and recorded. The patient's neuropathy was diagnosed by Michigan Neuropathy Screening Instrument (MNSI) ${ }^{26}$ and Douleur Neuropathic en 4 (DN4) diagnostic tool ${ }^{27}$. Those were diagnosed as DPNP and fulfilled the inclusion and exclusion criteria were enrolled in this study, and grouped into Group-A (received $300 \mathrm{mg}$ Gabapentine 12 hourly for 12 weeks) and Group-B (received $30 \mathrm{mg}$ Duloxetine 12 hourly for 12 weeks); no dose adjustment was allowed during the study period. Patients were followed-up by using 11-point numerical pain rating scale (NRS) ${ }^{28}$, patient's global impression of change (PGIC) score $^{29}$, and Clinical Global Impression of Change (CGIC) score ${ }^{30}$, treatment emergent adverse events (TEARs), vital signs, and body weight changes were recorded as efficacy and safety parameters.

Ethical approval taken form the Ethical Committee of Sylhet MAG Osmani Medical College. Furthermore, informed written consent was taken from the each of the participants. They were assured to keep their data confidential and they had full right to withdraw themselves from the study at any moment. Data were analyzed using SPSS, 12.0 version. Appropriate statistical methods were used based on the data. A probability value of $<0.05$ was considered statistically significant.

\section{Results:}

There were 72 diabetic patients with DPNP of both sexes recruited in both study groups equally in this study. Eight patients removed themselves and finally 33 patients in Group-A and 31 patients in Group-B left finally for analysis. The groups were statistically similar in terms of their mean age $(p=0.677)$, sex distribution $(p=0.222)$, duration of diabetes $(p=0.602)$, duration of DPNP $(p=0.301)$, mean RBS $(p=0.109)$, HbA1c $(p=0.54)$ and serum creatinine $(p=0.678)$. The MNSI, DN4, NRS and CGIC score were also similar between the study groups; $p$-values were $0.401,0.908,0.613$ and 0.758 respectively (Table I). 
Table-I: Baseline characteristics of the patients.

\begin{tabular}{lccc}
\hline Parameters & Group-A & Group-B & p-value \\
\hline Age (years) & $52.21 \pm 8.08$ & $51.32 \pm 8.90$ & $0.677^{*}$ \\
Sex & & & \\
$\quad$ Male & $11(33.3 \%)$ & $15(48.4 \%)$ & $0.222 \#$ \\
$\quad$ Female & $22(66.7 \%)$ & $16(51.6 \%)$ & \\
Duration of diabetes (years) & $6.79 \pm 3.81$ & $6.31 \pm 3.54$ & $0.602^{*}$ \\
Duration of DPNP (months) & $9.59 \pm 8.49$ & $7.60 \pm 6.62$ & $0.301^{*}$ \\
RBS (m.mol/L) & $12.04 \pm 3.54$ & $13.54 \pm 3.83$ & $0.109^{*}$ \\
HbA1c (\%) & $8.09 \pm 1.56$ & $8.32 \pm 1.40$ & $0.54^{*}$ \\
Serum Creatinine (m.mol/L) & $1.02 \pm 0.26$ & $1.05 \pm 0.20$ & $0.678^{*}$ \\
MNSI & $5.48 \pm 1.39$ & $5.21 \pm 1.20$ & $0.401^{*}$ \\
DN4 & $5.45 \pm 1.00$ & $5.48 \pm 1.02$ & $0.908^{*}$ \\
NRS & $6.70 \pm 1.16$ & $6.84 \pm 1.07$ & $0.613^{*}$ \\
CGIC & $3.61 \pm 0.93$ & $3.68 \pm 0.91$ & $0.758^{*}$ \\
\hline
\end{tabular}

*Unpaired t-test, \#Chi-Square test

Change in Numeric pain Rating Scale (NRS) score:

The score was $6.70 \pm 1.16$ in Group-A and $6.84 \pm 1.07$ in Group-B at baseline. The scores became $2.39 \pm 1.17$ and $2.55 \pm 1.21$ at 4 th week, $1.79 \pm 1.08$ and $1.97 \pm 1.08$ at 8 th week, and $1.6 \pm 0.96$ and $1.77 \pm 1.12$ at 12 th week in respected study groups. The scores were reduced significantly with the course of treatment within both groups ( $p=<0.001$ in both groups), but there was no significant difference observed between the groups at baseline $(p=0.613)$, 4th week $(p=0.605)$, 8th week $(p=0.508)$ and 12 th week $(p=0.598)$ (Figure 1).

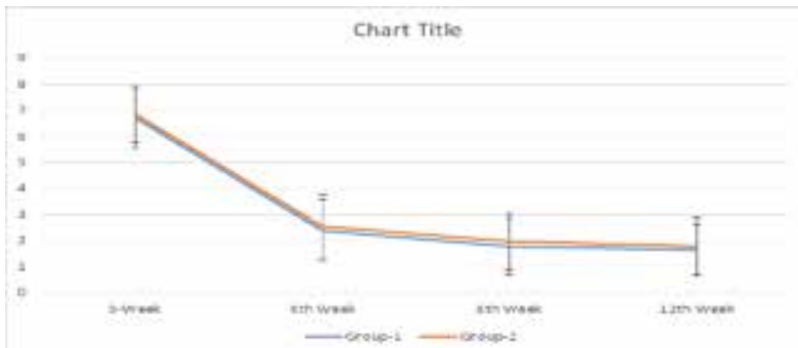

Figure-1: Change in the Numeric pain Rating Scale (NRS) score recorded at 0 -week, 4 th week, 8 th week and 12 th week of treatment. Change in Clinical Global Impression of Change (CGIC) severity at different time interval:

The score was $3.60 \pm 0.93$ in Group-A and $3.68 \pm 0.91$ in Group-B at baseline. The scores became $2.21 \pm 0.74$ and $2.22 \pm 0.92$ at 4 th week, $1.91 \pm 0.68$ and $1.87 \pm 0.67$ at 8 th week, and $1.73 \pm 0.57$ and $1.73 \pm 0.64$ at 12 th week in respected study groups. The scores were reduced significantly with the course of treatment within both groups ( $p=<0.001$ in both groups), but there was no significant difference observed between the groups at baseline $(p=0.758), 4$ th week $(p=0.324)$, 8th week $(\mathrm{p}=0.822)$ and 12 th week $(\mathrm{p}=0.908)($ Figure 2$)$.

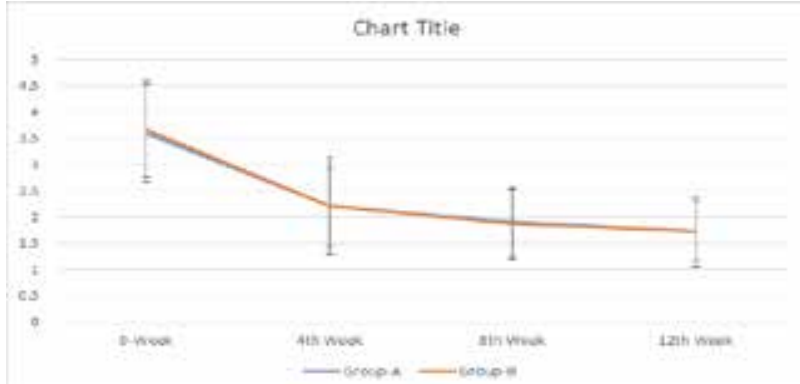

Figure-2: Change in Clinical Global Impression of Change (CGIC) severity score recorded before and 4 th week, 8 th week and 12 th week after the treatment.
Change in Patient Global Impression of Change (PGIC) score at different time interval:

In Group-A, the score was $2.42 \pm 0.94$ at 4 th week, $2.88 \pm 0.96$ at 8 th week, and $3.12 \pm 1.08$ at 12 th week of treatment. On the other hand, the score was $2.16 \pm 0.82$ at 4th week, $2.65 \pm 0.91$ at 8 th week, and $2.90 \pm 0.79$ at 12 th week in Group-B. The impression was improved significantly with the course of treatment within both groups $(\mathrm{p}=$ $<0.001$ in both groups), but there was no significant difference observed between the groups at 4 th week $(p=0.238)$, 8 th week $(p=0.323)$ and 12 th week $(p=0.364)($ Figure 3$)$.

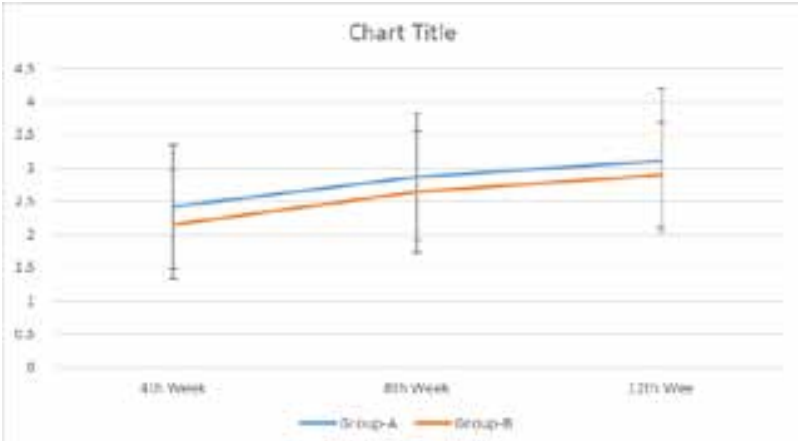

Figure-3: Change in Patient Global Impression of Change (PGIC) score recorded at 4 th week, 8 th week and 12 th week of the treatment.

Adverse effects: Overall distribution of adverse effects appeared in this study was found to be insignificant difference between the groups (Table-II). Observed adverse effects were dizziness, constipation, somnolence, peripheral edema, weight gain, dry mouth, nausea and/or vomiting. However, percentage of constipation $(p=0.022)$ and nausea-vomiting $(\mathrm{p}=0.01)$ in Duloxetine group observed significantly higher than the Gabapentine group.

Table-II: Distribution of patients adverse effects recorded at 4 th, 8 th, and 12 th week of treatment.

\begin{tabular}{lllc}
\hline Adverse effects & Group-A & Group-B & p-value \\
\hline Dizziness & $7(21.2 \%)$ & $2(6.5 \%)$ & $0.150^{*}$ \\
Constipation & $0(0 \%)$ & $5(16.1 \%)$ & $0.022^{*}$ \\
Somnolence & $4(12.1 \%)$ & $2(6.5 \%)$ & $0.238^{*}$ \\
Peripheral edema & $4(12.1 \%)$ & $0(0 \%)$ & $0.114^{*}$ \\
Weight gain & $1(3.0 \%)$ & $0(0 \%)$ & $1.00^{*}$ \\
Dry mouth & $0(0 \%)$ & $2(6.5 \%)$ & $0.231^{*}$ \\
Nausea-vomiting & $0(0 \%)$ & $6(19.4 \%)$ & $0.01^{*}$ \\
\hline Total & $\mathbf{1 3 ( 3 9 . 4 \% )}$ & $\mathbf{1 1 ( 3 5 . 5 \% )}$ & $\mathbf{0 . 7 4 7 \#}$ \\
\hline
\end{tabular}

\section{Discussion:}

Neuropathic pain is often associated with diabetic peripheral neuropathy and is defined as pain initiated of caused by a primary lesion or dysfunction in the nervous system ${ }^{31}$. A major goal of pharmacologic treatment on DPNP is to control pain. Simple analgesic may provide partial, short-term relief, but more specifically targeted drugs are normally required for sustained control of pain of neuropathic origin ${ }^{31}$.

Gabapentine was approved in 2004 for the treatment of peripheral neuropathic pain in Europe, and in 2005 for the treatment of neuropathic pain associated with diabetic peripheral neuropathy and post herpetic neuralgia in the 
US. Duloxetine is a relatively balanced and potent reuptake inhibitor of serotonin and nor-epinephrine, approved in the Europe and the US for the treatment of DPNP.

This study was conducted to compare the efficacy and tolerability of Duloxetine, which is approved for the treatment of DPNP, with formerly licensed agent Gabapentine. In this study, there was significant reduction in mean Numeric painRating Scale (NRS) score and Clinical Global Impression of Change (CGIC) severity score in both Gabapentine and Patient Global Impression of Change (PGIC) score also improved significant in both groups after the treatment. However, there was no significant difference observed between the study groups in NRS score, CGIC severity score and PGICscore at 4th week, 8th week, and 12th week of treatment. The study of Devi et al..$^{32}$ also reported similar observation at the end of the study. Compared to their result, this study also showed relatively similar reduction in NRS and CGIC in during first follow-up (4th week); but Gabapentine showed more steep and faster reduction than Duloxetine and Gabapentin in their study.

Similar significant improvement in Gabapentine and Duloxetine taking patients with DPN also reported in several studies. Quilicis et al. ${ }^{31}$, Devi et al. ${ }^{32}$, Goldstein et al., ${ }^{33}$ Baron et al. ${ }^{34}$ and Tolle et al. ${ }^{35}$ reported significant improvement in daily pain score compare to placebo and other comparable drugs. Significant reduction in CGIC score reported by Wernicke et al., ${ }^{36}$ Tolle et al., ${ }^{35}$ Baron et al., ${ }^{34}$ and Gao et al., ${ }^{37}$ in comparison with placebo and other comparable drugs. Greater improvement in PGIC score showed by Wernicke et al., ${ }^{36}$ and Gao et al., ${ }^{37}$ also compared with placebo and other drugs. Tolle et al..$^{35}$ showed better improvement in Gabapentine taking group compared to placebo $(\mathrm{p}=0.02)$. Devi et al. ${ }^{32}$ also showed significantly higher response by Gabapentine than Duloxetine in PGIC scores, whereas, this study showed similar effect by both drugs. Disparaging report presented by Tanenberg et al., ${ }^{25}$ where they showed some changes in daily pain score and CGIC severity score, but they were statistically insignificant.

Adverse effects in this study were mild in intensity and drug discontinuation was not needed. In Gabapentine group, 39.4\% patients experienced development of adverse effects, and $35.5 \%$ patients were suffered. Tolerability profile in this study was generally consistent with previous studies. ${ }^{31,33}$ Devi et al. ${ }^{32}$ reported lower rate $(9.2 \%)$ of development of adverse effect, those were mild, self-limiting and did not require to discontinuation of therapy. Tanenberg et al. ${ }^{25}$ reported higher adverse effects $(p=0.04)$ in Duloxetine group than Gabapentine group.

\section{Conclusion:}

Monotherapy either Gabapentine or Duloxetin produced substantial pain relief, while none of the drug appeared superior at the 12-weeks of treatment in patients with DPNP. Overall, all treatments were well tolerated with minor side effects. In conclusion, Gabapentine and Duloxetine are equally effective in treatment of DPNP with good safety profile.

\section{Conflict of Interest: None.}

Acknowledgement:

The authors are thankful to the study subjects for their active, sincere and voluntary participation. The authors are also thankful to the medical officer, nursing staff, and laboratory staff for their kind support. It is of my great pleasure to express my deepest regards to my respected teacher Professor Dr. A. K. M. Mosharrof Hossain and Professor Dr. Md. Ruhul Amin.

\section{References:}

1. American Diabetes Association. Economic costs of diabetes in the US in 2007. Diabetes Care. 2008; 36:596-615.

https://doi.org/10.2337/dc08-9017

PMid:18308683

2. World Health Organization. World Diabetes: A Newsletter. 1997 September: 3-6.

3. Frier BM, Fisher M. Diabetes Mellitus, in Davidson's Principles and Practice of Medicine, Colledge NR, Walker BR, Ralston SH (eds.). 21st ed. Churchill Livingstone: China; 2010: 818-832.

4. Khardori R. Type 2 Diabetes Mellitus, Emedicine [online]. Updated: June 24 2013. Available from: http://emedicine.medscape.com/article/117853. [23 August 2013] 5. Sun P, Zhao Y, Zhao Z, Bernauer M, Watson P. Dosing pattern comparison between duloxetine and pregabalin among patients with diabetic peripheral neuropathic pain. Pain Practice. 2012; 12(8):641-648.

https://doi.org/10.1111/j.1533-2500.2012.00537.x

PMid:22335435

6. Gregg EW, Sorlie P, Paulose-Ram R, Gu Q, Eberhardt MS, Wolz M, et al. Prevalence of lower extremity disease in the US adult population $>40$ years of age with and without diabetes: 1999-2000 national health and nutrition examination survey. Diabetes Care. 2004; 27:1591-1597.

https://doi.org/10.2337/diacare.27.7.1591

PMid:15220233

7. Sadosky A, McDermott AM, Brandenburg NA, Strauss M. A review of the epidemiology of painful diabetic peripheral neuropathy, post-herpetic neuralgia, and less commonly studied neuropathic pain conditions. Pain Practice. 2008; 8:45-56.

https://doi.org/10.1111/j.1533-2500.2007.00164.x

PMid:18211592

8. Diabetes UK. Diabetes in the UK 2010: key statistics on diabetes, available: last accessed. 21st January 2011.

9. Prasad K, Priyanga, Ranil J, Godwin RC, Rezvi SMH, Matthews DR. The prevalence, pattern and predictors of diabetic peripheral neuropathy in a developing country. Diabetology and Metabolic Syndrome. 2012; 4:21.

https://doi.org/10.1186/1758-5996-4-21

PMid:22642973 PMCid:PMC3408375 
10. Erbas T, Ertas M, Yucel A, Keskinaslan A, Senocak M. Prevalence of peripheral neuropathy and painful peripheral neuropathy in Turkish diabetic patients. Journal of Clinical Neurophysiology. 2011; 28(1):51-55.

https://doi.org/10.1097/WNP.0b013e3182051334

PMid:21221008

11. Wu EQ, Borton J, Said G, Le TK, MonzB, Rosilio M, et al. Estimated prevalence of peripheral neuropathy and associated pain in adults with diabetes in France. Current Medical Research and Opinion. 2007; 23(9):2035-2042.

https://doi.org/10.1185/030079907X210516

PMid:17637204

12. Colin IM, Bouhassira D, Weiss S, Matthys K, Mathieu C, Van-Acker K. Prevalence of polyneuropathy and neuropathic pain in type-1 and type-2 diabetic patient with metabolic syndrome parameters. Diabetes. 2007; 56:209.

https://doi.org/10.1016/j.ejpain.2007.03.275

13. Dutta A, Naorem S, Singh TP, Wangjam K. Prevalence of peripheral neuropathy in newly diagnosed type 2 diabetes mellitus. International Journal of Diabetes in Developing Countries. 2005; 25:30-33.

https://doi.org/10.4103/0973-3930.26756

14. Khuwaja AK, Rafique G, White F, Azam SI. Macrovascular complications and their associated factors among persons with type 2 diabetes in Karachi, Pakistan - a multi-center study. Journal of Pakistan Medical Association. 2004; 54:60-66.

15. Morkrid K, Alin L, Hussain A. Risk factors and prevalence of diabetic peripheral neuropathy: a study of type 2 diabetic outpatients in Bangladesh. International Journal of Diabetes in Developing Countries. 2010; 28(1):11-17.

https://doi.org/10.4103/0973-3930.60004

PMid:20431800 PMCid:PMC2859278

16. Lin HC. Diabetic Neuropathy, Emedicine [online]. Updated Jul 9, 2012. Available from: http://emedicine.medscape.com/article/1170337. [23 August 2013]

17. Ziesgler D. Treatment of diabetic neuropathy and neuropathic pain: how far have we come? Diabetes Care. 2008; 31(Supppl.2):S255-S261.

18. Zhao Y, Sun P, Watson P, Mitchell BRS. Comparison of medication adherence and healthcare costs between duloxetine and pregabalin initiators among patients with fibromyalgia. Pain Practice. 2011; 11:204-216.

https://doi.org/10.1111/j.1533-2500.2010.00412.x

https://doi.org/10.1111/j.1533-2500.2010.00431.x

19. Jensen MP, Chodroff MJ, Dworkin RH. The impact of neuropathic pain on health-related quality of life: review and implications. Neurology. 2007; 68:1178-1182.

https://doi.org/10.1212/01.wnl.0000259085.61898.9e

PMid: 17420400
20. Finnerup N, Otto M, McQuay HJ, Jensen TS, Sindrup $\mathrm{SH}$. Algorithm for neuropathic pain treatment: an evidence based proposal. Pain. 2005; 118:289-305.

https://doi.org/10.1016/j.pain.2005.08.013

PMid:16213659

21. Argoff CE, Cole BE, Fishbain DA, Irving GA. Diabetic peripheral neuropathic pain: clinical and quality-of-life. Mayo Clinic Proceedings. 2006; 81(Suppl.4):S3-S11.

https://doi.org/10.1016/S0025-6196(11)61474-2

22. Robinson-Papp J, Simpson DM. Safety profile of treatment in diabetic peripheral neuropathic pain. Pain Medicine. 2007; 8(Suppl. 2):S43-S49.

https://doi.org/10.1111/j.1526-4637.2007.00351.x

PMid:17714115

23. Raskin J, Pritchett YL, Wang F, D'Souza DN, Waninger $\mathrm{AL}$, Lyengar $\mathrm{S}$, et al. A double-blind, randomized multi-center trial comparing duloxetine with placebo in the management of diabetic peripheral neuropathic pain. Pain Medicine. 2005; 6(5):346-356.

https://doi.org/10.1111/j.1526-4637.2005.00061.x

PMid:16266355

24. Gore M, Zlateva G, Tai K, Chandran A, Leslie D. Retrospective evaluation of clinical characteristics, pharmacotherapy and healthcare resource use among patients prescribed pregabalin or duloxetine for diabetic peripheral neuropathy in usual care. Pain Medicine. 2011; 11:167-179.

https://doi.org/10.1111/j.1533-2500.2010.00415.x

PMid:20723096

25. Tanenberg RJ, Irving GA, Risser RC, Ahl J, Robinson MJ, Skljarevski V. Duloxetine, pregabalin, and duloxetine plus gabapentine for diabetic peripheral neuropathic pain management in patients with inadequate pain response to gabapentin: and open-label, randomized, noninferiority comparison. Mayo Clinic Proceedings. 2011; 86(7): 615-624.

https://doi.org/10.4065/mcp.2010.0681

PMid:21719618 PMCid:PMC3127557

26. Feldman EL, Stevens MJ, Thomas PK, Brown MB, Canal N, Greene DA. A practical two-step quantitative clinical and electrophysiological assessment for the diagnosis and staging of diabetic neuropathy. Diabetes Care. 1994; 17(11):1281-1289.

https://doi.org/10.2337/diacare.17.11.1281

PMid:7821168

27. Bouhassira D, Attal N, Alchaar H, Boureau F, Brochet $\mathrm{B}$, Bruxelle J, et al. Comparison of pain syndromes associated with nervous or somatic lesions and development of a new neuropathic pain diagnosis questionnaire (DN4). Pain. 2005; 114(1-2):29-36.

https://doi.org/10.1016/j.pain.2004.12.010

PMid:15733628 
28. McCaffer M, Pasero C. Pain: Clinical manual. St. Louis. Copyrighted by Mosby company, reprinted with permission. 1999.

29. Hurst H, Bolton J. Assessing the clinical significance of change scores recording on subjective outcome measures. Journal of Manipulative and Physiological Therapeutics. 2004; 27(1):26-35.

https://doi.org/10.1016/j.jmpt.2003.11.003

PMid:14739871

30. Guy W. (1976). Early clinical drug evaluation unit (ECDEU) assessment manual for psychopharmacology. Revised. NIMH publication DHEW publNO (Adm) 76-338. Bethesda MD: National Institute of Mental Health, 1976; 217-222.

31. Quilici S, Chancellor J, Lothgren M, Simon D, Sad G, Kim Le T, et al. Meta-analysis of duloxetine vs. pregabalinana gabapentin in the treatment of diabetic peripheral neuropathic pain. BioMed Central Neurology. 2009; 9:6.

https://doi.org/10.1186/1471-2377-9-6

PMid:19208243 PMCid:PMC2663537

32. Devi P, Madhu K, Ganapathy B, Sarma GRK, John L, Kulkarni C. Evaluation of efficacy and safety of gabapentin, duloxetine, and pregabalin in patients with painful diabetic peripheral neuropathy. Indian Journal of Pharmacology. 2012; 44(1):51-56.

https://doi.org/10.4103/0253-7613.91867

PMid:22345870 PMCid:PMC3271540
33. Goldstein DJ, Lu Y, Detke MJ, Lee TC, Iyengar S. Duloxetine vs. placebo in patients with painful diabetic neuropathy. Pain. 2005; 2:109-118.

https://doi.org/10.1016/j.pain.2005.03.029

PMid:15927394

34. Baron R, Brunnmuller U, Brasser M, May M, Binder A. Efficacy and safety of pregabalin in patients with diabetic peripheral neuropathy or postherpetic neuralgia: open-label, non-comperative, flexible-dose study. European Journal Pain. 2008; 12(7):850-858.

https://doi.org/10.1016/j.ejpain.2007.12.004

PMid:18242109

35. Tolle T, Freynhagen R, Versavel M, Trostmann U, Young JPJr. Pregabalin for relief of neuropathic pain associated with diabetic neuropathy: a randomized. Double-blind study. European Journal of Pain. 2008; 12(2):203-213.

https://doi.org/10.1016/j.ejpain.2007.05.003

PMid: 17631400

36. Wernicke JF, Pritchett YL, D'Souza DN, Waninger A, Tran P, Iyengar S, et al. A randomized controlled trial of duloxetine in diabetic peripheral neuropathic pain. Neurology. 2004; 67(8):1411-1420.

https://doi.org/10.1212/01.wnl.0000240225.04000.1a

PMid:17060567

37. Gao Y, Ning G, Jia WP, Zhou ZG, Xu ZR, Liu ZM, et al. Duloxetine versus placebo in the treatment of patients with diabetic neuropathic pain in China. Chinese Medical Journal. 2010; 123(22):3184-3192. 